\title{
Management of mental illness by the British Army
}

\author{
LEIGH A. NEAL, MATTHEW KIERNAN, DAVID HILL, FRANK McMANUS \\ and MARK A. TURNER
}

\section{Background The Ministry of Defence has its own hospital for soldiers requiring admission for mental health problems.}

Aims Toassess the efficiency ofthe army psychiatric hospital at restoring patients to full active duty. To assess whether a new military training and rehabilitation unit (MTRU) that emphasises military-skills training, improves outcome.

Method A 2-year, inception-cohort outcome study of hospital in-patients. A 12-month, case-matched,"before and after' outcome study compared MTRU patients with hospital in-patients.

Results I (hospital in-patients, $n=309$ ): at 2-year follow-up 67 (22\%) were fully fit for active duty. Military psychiatrists' success rate at predicting recovery to active duty was $27 \%$. 2: the odds of a soldier in the MTRU cohort $(n=35)$ returning to active duty were 14 times greater than for the hospital cohort $(n=35)$. The odds of remaining in the army while unf it for active duty were 20 times less for the MTRU than for the hospital cohort.

\section{Conclusions The army hospital is} inefficient at rehabilitation to active duty. The MTRU significantly increased the odds of returning to active duty and reduced the odds of remaining in the army while still unfit. These findings may be applicable to the emergency services.

Declaration of interest None. The views expressed in this paper are not necessarily those of the Ministry of Defence or Her Majesty's Government.
The Ministry of Defence is unique among the state sector services for running its own secondary care mental health service, which is independent of the National Health Service. This was born of the necessity to provide health care to troops on operations overseas and to provide fast-track treatment in the UK to keep the armed forces fit and ready for deployment. The uniformed mental health care system in the military has continued largely as a legacy of the Second World War (Shephard, 2000), with the addition of a community mental health service in the 1970s. In the UK, until 1995, army personnel were admitted to the psychiatric ward at the Queen Elizabeth Military Hospital in Woolwich, and since 1995 they have been admitted to the tri-service psychiatric unit at the Duchess of Kent's Psychiatric Hospital (DKPH) in Catterick Garrison.

The British Army is at present simultaneously involved in peace support operations in Northern Ireland, Cyprus, Bosnia, Kosovo, Sierra Leone and Afghanistan, leading to a continuing and pressing requirement for trained, fit personnel. The present full-time trained requirement of the British Army is 106973 and the trained strength is 100378 (Defence Analytical Services Agency, 2001). All uniformed personnel are employed on the basis that they have an operational role overseas. It is therefore essential that the largest possible percentage of the fighting force is operationally fit, which requires full mental fitness.

About 3000 personnel present to secondary care mental health services in the army per year and about 260 army personnel are admitted to DKPH per year (Duchess of Kent's Psychiatric Hospital, 2001). This represents a psychiatric admission rate of about 2.6 per 1000 army personnel per year. At the time of discharge from the in-patient psychiatric unit each soldier is classified, by a consultant military psychiatrist, according to instructions (Ministry of Defence, 2000) as follows:

(a) recommended for discharge from the army;

(b) psychologically unfit for military operational deployment, but likely to become fit during the next 18 months;

(c) psychologically fit for military operational deployment.

Soldiers in category (b) may have additional temporary occupational restrictions attached to their continued employment, such as 'unfit live arms', and they are not permitted to go on operational tours. They therefore represent a group of army personnel who are continuing to be paid by the Ministry of Defence and who are being provided with out-patient treatment by the Ministry of Defence, but who are unfit for their primary operational role.

The occupational outcome of soldiers requiring in-patient care for mental illness is not known. In view of internal concerns about the number of medically unfit soldiers in the British Army, an investigation was designed in two stages: the first to identify the 2-year occupational outcome of soldiers admitted to an army psychiatric hospital, and the second to assess the effectiveness of a new military rehabilitation unit in terms of occupational outcome.

\section{METHOD}

\section{Stage I}

This phase of the study was designed to determine the occupational outcome of army personnel discharged from DKPH (but retained in the army) at 6 months, 12 months, 18 months and 24 months after discharge, as well as to assess the predictive ability of military psychiatrists to determine occupational outcome.

\section{Data collection}

Baseline data on an inception cohort of consecutive hospital admissions were collected prospectively over a 14-month period at DKPH; 310 consecutively admitted Army personnel were entered into the study. At the time of follow-up analysis, 2 years later, demographic data were missing for one person, leaving a cohort of 309 $(97.7 \%)$ persons followed up for 2 years after discharge. The follow-up information was obtained from the Army Personnel Centre in Glasgow. 
Data were recorded in terms of age, gender, diagnosis and occupational recommendations on discharge. Outcome for each soldier was recorded categorically in terms of fitness for operational deployment in the 6 months, 12 months, 18 months and 24 months after discharge.

\section{Stage 2}

On the basis of the findings in the first stage of this study an experimental assessment and treatment unit was instituted for a 12-month period at DKPH (the tri-service psychiatric hospital). The details of the operation of this unit, named the Military Training and Rehabilitation Unit (MTRU), are described in the Appendix. The MTRU was designed to increase the number of soldiers restored to full operational fitness and to reduce the cost to the Ministry of Defence of employing non-effective soldiers. The aim of the study was to report data on the effectiveness of the MTRU by comparing the occupational outcome at 6 months and 12 months after hospital discharge with the traditional stand-alone in-patient psychiatric treatment.

\section{Sample}

The study was to be a controlled 'before and after' design and this required a sample of patients managed by the MTRU to be matched with a sample admitted to hospital before the MTRU was established. Commissioned officers and warrant officers were not admitted to the MTRU because of their unsuitability to the basic training aspects of the rehabilitation regimen. An index group of consecutive MTRU patients were selected according to the following criteria:

(a) admitted to DKPH after the MTRU was established;

(b) referred directly from the in-patient ward;

(c) completed the full rehabilitation and assessment process.

A control sample was selected by matching the three-digit ICD-10 diagnoses (World Health Organization, 1992) of the MTRU sample, using consecutive patients admitted to DKPH between 1 January 1996 and 1 January 1999. All ICD-10 diagnoses were made by consultant psychiatrists.

\section{Statistics}

Data were statistically analysed using Pearson's chi-squared test for categorical data and the independent $t$-test for continuous data. The characteristics of the index and control groups were compared. Outcome was assessed separately in the period 0-6 months and 6-12 months following discharge from hospital. Odds ratios with $95 \%$ confidence intervals were calculated to determine the significance of the MTRU intervention.

\section{RESULTS}

\section{Stage I}

\section{Sample characteristics}

Of the 309 army personnel in the study sample, $20(6.5 \%)$ were women and the mean age was 26.4 years (range 17-53 years, s.d.=6.9). Table 1 shows the distribution of their primary psychiatric diagnoses according to ICD-10 (World Health Organization, 1992).

\section{Rehabilitation to operational fitness}

The operational fitness of the subgroup of army personnel discharged from hospital and retained by the army was followed up over 24 months at 6-month intervals. From the inception cohort of 309 soldiers, 78 $(25 \%)$ were operationally fit in the period 0-6 months after their discharge from hospital, $54(17 \%)$ at 6-12 months, 47 (15\%) at $12-18$ months and $67(22 \%)$ at $18-24$ months. It can therefore be predicted from the 2-year outcome data that about 56 $(22 \%)$ of the 260 soldiers admitted to DKPH each year will eventually become fully fit for operational deployment.

The conservative estimate of the total cost of employing the army personnel in this study who were unfit for operational deployment, in the 24-month period following psychiatric hospital discharge, was $£ 3614567$. This equates proportionately to a cost of about $£ 3$ million per year to continue to employ operationally unfit army personnel following their admission to the army psychiatric hospital.

\section{Predicting recovery}

After 2 years 161 (52\%) soldiers had been recommended for discharge on psychiatric grounds and $70(22.7 \%)$ had left for other reasons, such as the end of their contracted period of service or administrative discharge. This group also includes 3 soldiers who died while still serving. Military psychiatrists predicted that 196 of this cohort, who were unfit for operational deployment at the time of hospital discharge, were worth retaining in the army because they were likely to become fit within 18 months. The predictive success rate of the military psychiatrists, in terms of the number of these 196 army personnel actually becoming operationally fit, was $4.6 \%$ at 6-12 months, $15.8 \%$ at $12-18$ months and $27 \%$ at $18-24$ months.

\section{Stage 2 \\ Sample characteristics}

Between 1 February 2001 and 1 March 2002 a total of 65 soldiers were admitted and discharged from the MTRU. Twentynine of these were excluded from the study on the basis of the selection criteria described above: 15 of the 29 had been admitted to DKPH before the MTRU was established and 14 were referrals from community agencies outside DKPH. After these exclusions 36 remained in the index group. These were matched consecutively and as closely as possible for ICD-10 diagnosis with the cohort of patients admitted to DKPH between 1 January 1996 and 1 January 1999. It was not possible to find a suitable match for a case of anorexia nervosa (ICD-10, F50.1) and so this patient was excluded, leaving 35 persons in the index sample. Table 2 lists the distribution of ICD-10 diagnoses in the two samples. There was no significant difference in the distribution of diagnoses between the two

Table I Distribution of primary psychiatric disorders in terms of ICD-10 for 309 army personnel admitted consecutively to the Duchess of Kent's Psychiatric Hospital from I January 1996 to I January 1999

\begin{tabular}{lr}
\hline Psychiatric disorder & $\%$ \\
\hline $\begin{array}{l}\text { Neurotic, stress-related and somatoform } \\
\text { disorders }\end{array}$ & 32.6 \\
Alcohol or drug misuse & 26.4 \\
Psychosocial and environmental problems & 13.2 \\
Depressive episode & 12.5 \\
Personality disorder & 9.9 \\
Schizophrenia, schizotypal and delusional & 3.3 \\
$\quad$ disorders & \\
Organic personality change & 1.2 \\
Bipolar affective disorder & 0.9
\end{tabular}

I. Only one soldier had a primary diagnosis of posttraumatic stress disorder. 
samples $\quad\left(\chi^{2}=6.09, \quad\right.$ d.f. $\left.=15, \quad P=0.978\right)$. Table 3 compares the two samples in terms of age, gender, marital status, rank and length of hospital admission. All the characteristics were matched except for marital status $(P<0.01)$.

\section{Rehabilitation to operational fitness}

Table 4 compares the outcomes using odds ratios in terms of occupational recommendations 0-6 months after hospital discharge. Table 5 compares the outcomes using odds ratios in terms of the number of soldiers leaving the army for other reasons and the occupational recommendations for the remainder 6-12 months after hospital discharge.

\section{DISCUSSION}

The rehabilitation of army personnel admitted to the military psychiatric hospital (DKPH) is poor. Less than a quarter of these patients become fully operationally fit during the 24 months following their discharge from hospital. Military psychiatrists' ability to predict which patients will recover full operational fitness is poor, with a hit rate of only $27 \%$ by 24 months after hospital discharge. The army continues to employ soldiers who are not operationally fit for up to 2 years following a hospital admission. These soldiers are not fulfilling their primary role and can be difficult to employ gainfully at their base units over long periods.

Outcome data from the MTRU intervention study (Tables 4 and 5) show that soldiers rehabilitated by the MTRU are 5 times more likely to be psychologically fit for operations 0-6 months after hospital discharge than if they had been treated traditionally. At 6-12 months soldiers rehabilitated by the MTRU are 14 times more likely to be psychologically fit for operations than if they had been treated traditionally. Therefore, as time progresses, there appears to be an increase in the odds of soldiers in the MTRU group being fully rehabilitated. Overall, these findings indicate the potential for a significant increase in the number of soldiers becoming fit for operational duty in the 12 months after hospital discharge following rehabilitation by the MTRU.

Soldiers rehabilitated by the MTRU are 20 times less likely to be graded as operationally unfit and retained than those managed in the traditional setting, in the period
Table 2 Distribution of ICD-10 diagnoses in the Military Training and Rehabilitation Unit (MTRU) and control groups

\begin{tabular}{|c|c|c|}
\hline Psychiatric diagnosis (ICD-10 code) & $\operatorname{MTRU}(n=35) n(\%)$ & Controls $(n=35) n(\%)$ \\
\hline Adjustment disorder (F43.2) & $12(34)$ & $12(34)$ \\
\hline Moderate depressive episode (F32.I) & $5(14)$ & $6(17)$ \\
\hline Schizophrenia, unspecified (F20.9) & $3(9)$ & $3(9)$ \\
\hline Emotionally unstable personality disorder (F60.3) & $3(9)$ & $3(9)$ \\
\hline Severe depressive episode (not psychotic) (F32.2) & $2(6)$ & $2(6)$ \\
\hline Alcohol dependence syndrome (FI0.2) & $2(6)$ & $2(6)$ \\
\hline Mild depressive episode (F32.0) & $2(6)$ & I (3) \\
\hline Generalised anxiety disorder (F4I.I) & $2(6)$ & I (3) \\
\hline Opioid dependence syndrome (FII.2) & I (3) & I (3) \\
\hline Other acute and transient psychotic disorder (F23.8) & I (3) & I (3) \\
\hline Bipolar affective disorder, unspecified (F3I.9) & I (3) & I (3) \\
\hline Symptoms but no psychiatric disorder (Z00.4) & I (3) & I (3) \\
\hline Mixed anxiety and depressive disorder (F4I.2) & $0(0)$ & I (3) \\
\hline
\end{tabular}

Table 3 Characteristics of the Military Training and Rehabilitation Unit (MTRU) and control groups

\begin{tabular}{lccc}
\hline & MTRU $(n=35)$ & Controls $(n=35)$ & $P$ (two-tailed) \\
\hline Age in years, mean (s.d.) & $24.3(5.5)$ & $25.8(5.5)$ & 0.214 \\
Days spent in hospital, mean (s.d.) & $93.5(68.2)$ & $120.0(134.0)$ & 0.311 \\
Females ( $n)$ & 6 & 3 & 0.239 \\
Married $(n)$ & 5 & 16 & $0.004^{*}$ \\
Private rank $^{2}(n)$ & 28 & 23 & 0.072 \\
\hline
\end{tabular}

I. Includes time in the MTRU for the index group.

2. Ranks categorised into 'privates' and 'non-commissioned officers'.

$* P<0.01$.

Table 4 Outcome in the period 0-6 months after psychiatric hospital discharge: comparison between the MilitaryTraining and Rehabilitation Unit (MTRU) and control groups

\begin{tabular}{lcccc}
\hline Outcome & MTRU & $\begin{array}{c}\text { Control } \\
\text { Psychologically unfit for further service in the army }\end{array}$ & \multicolumn{1}{c}{$n$} & \multicolumn{1}{c}{$\begin{array}{c}\text { Odds ratio } \\
(95 \% \mathrm{Cl})\end{array}$} \\
\hline Not fit for military operations (but likely to become fit) & 4 & 6 & $2.86(0.94-8.7 \mathrm{I})$ \\
Psychologically fit for military operations & 18 & 23 & $0.07(0.02-0.24)^{1}$ \\
Total & 35 & 35 & $5.12(1.70-15.39)^{\prime}$
\end{tabular}

I. Significant odds ratio $(95 \% \mathrm{Cl}$ does not include 1.0$)$.

Table 5 Outcome in the period 6-12 months after hospital discharge: comparison between the Military Training and Rehabilitation Unit (MTRU) and control groups

\begin{tabular}{|c|c|c|c|}
\hline Outcome & $\begin{array}{c}\text { MTRU } \\
n\end{array}$ & $\begin{array}{c}\text { Control } \\
n\end{array}$ & $\begin{array}{c}\text { Odds ratio } \\
(95 \% \mathrm{Cl})\end{array}$ \\
\hline Departed from the army for non-medical reasons ${ }^{\prime}$ & 4 & 9 & $0.37(0.10-1.35)$ \\
\hline Psychologically unfit for further service in the army & 14 & II & $1.45(0.54-3.89)$ \\
\hline Not fit for military operations (but likely to become fit) & I & 13 & $0.05(0.0 \mathrm{I}-0.4 \mathrm{I})^{2}$ \\
\hline Psychologically fit for military operations & 16 & 2 & $13.89(2.88-67.10)^{2}$ \\
\hline Total & 35 & 35 & \\
\hline
\end{tabular}

I. During the previous 6-month period.

2. Significant odds $(95 \% \mathrm{Cl}$ does not include 1.0$)$. 
6-12 months after hospital discharge (Table 5). This indicates that the MTRU is better at assessing risk and reducing the imposition of unnecessary occupational restrictions than is the traditional in-patient setting.

The results from the first stage of this study indicate that the MoD pays over $£ 3$ million per year to retain operationally unfit soldiers following psychiatric hospital admission. This figure is conservative because the additional cost of employing ranks above that of private was not calculated. The second stage of this study demonstrates the potential for a significant saving in these costs, with the MTRU. However, the relative cost of treatment is an important additional consideration. There was no significant difference in the duration of hospitalisation between the two study groups (Table 3), although the mean period of hospitalisation of the MTRU group was paradoxically 26 days less than the mean for the control group. Treatment costs per day in the MTRU were less than the costs of the traditional wardbased treatment because of a lower staffto-patient ratio. In this study, the MTRU option was thus less expensive than the traditional form of in-patient treatment in terms of total treatment costs.

\section{Limitations}

The second stage of this study may have been limited by a number of factors. First, the study was not designed as a randomised controlled trial because it was anticipated that soldiers would have reasonable grounds for objecting to their terms of service being partly determined by chance. In these circumstances, the controlled 'before and after' design was the most practical and methodologically sound evaluation available. The strength of quasi-experimental studies lies in their 'real world' applicability (Cook \& Campbell, 1979; Gilbody \& Whitty, 2002).

Second, there may also have been a selection bias towards individuals with a better prognosis entering the MTRU. Officers and warrant officers were not admitted to the MTRU, but this was controlled for in the matched sample in the second stage. Hospital in-patients were selected to transfer to the MTRU primarily on the basis of their capacity for independent living, and the first stage results indicate an inability of clinicians to detect patients with a better prognosis. All army patients

\section{CLINICAL IMPLICATIONS}

The rehabilitation of British soldiers after admission to a traditional in-patient psychiatric unit was poor, with only $22 \%$ returning to full operational fitness in the 2 years after discharge from hospital.

- The development of a specialised military rehabilitation unit, as an adjunct to inpatient care, significantly improved the 12-month outcome in terms of the odds of returning soldiers to full operational fitness.

- The findings from this study may have implications for improving the management of mental illness in other front-line emergency services.

\section{LIMITATIONS}

- For practical reasons the study was not randomised but it used a next-best controlled 'before and after' quasi-experimental design.

- Substance use disorders were underrepresented in the controlled 'before and after' study compared with the normal case-mix.

- There was a significantly greater number of married soldiers in the control group than in the index rehabilitation group.

LEIGH A. NEAL, MD, St James's University Hospital, Leeds; MATTHEW KIERNAN, BSc, DAVID HILL, MSc, FRANK McMANUS, MRCPsych, MARK A. TURNER, MRCPsych, Duchess of Kent's Psychiatric Hospital, Catterick Garrison, North Yorkshire, UK

Correspondence: Dr Leigh A. Neal, Bristol Priory Hospital, Heath House Lane, Stapleton, Bristol BSI6 IEQ,UK.Tel: 01666 8244I0; e-mail: leigh@psychconsserv.fsnet.co.uk

(First received 7 May 2002, final revision 24 September 2002, accepted I November 2002)

admitted to DKPH become fit for independent living prior to discharge from hospital because of the acute nature of their illness. Therefore, although patients could not be admitted to the MTRU until they had become fit for independent living for practical reasons, this is unlikely to have introduced a selection bias in terms of the longer-term outcome.

Third, the proportion of substance misuse cases in the MTRU ( $9 \%$, Table 2$)$ is less than the proportion found in all DKPH hospital admissions (26.4\%, Table 1). This was because of a declared bias against admission of people with this diagnosis to the MTRU by the clinical team managing substance misuse (however, this was controlled for in the matched sample in the second stage). Therefore, the study results cannot be generalised to include all patients with a diagnosis of substance misuse.
Finally, members of the index group were significantly less likely to be married than the control group (Table 3). Therefore, the MTRU group might be considered less stable in the absence of a confiding relationship. This does not explain the comparative increase in the number of those fully rehabilitated by the MTRU, which might be expected to run counter to this effect. This selection bias does not appear to influence the interpretation of the results.

It was the impression of the clinical staff that the success of the MTRU was attributable to an improved risk assessment, based on the ability to observe the behaviour of the patients in a simulated military environment, and to the increased self-confidence in military skills acquired by the patients. This allowed the clinical staff to return more soldiers to duty 
without occupational restrictions, physically fit and confident in their military skills. These factors combined to reduce stigmatisation at the soldiers' units, enabling rapid and effective reintegration.

The approach to rehabilitation described in this study may be transferable to other sectors, such as the police, fire, ambulance and other emergency services, which may experience similar difficulties in the effective rehabilitation of employees with psychiatric problems to front-line duties.

\section{APPENDIX}

Military Training and Rehabilitation Unit (MTRU)

\section{Location and resources}

Located next to the psychiatric in-patient unit. Contains 27 beds in single-room, barrack-style accommodation

\section{Admission criteria}

Patients are:

selected for admission to the MTRU from the inpatient ward;

screened with a risk assessment tool for the capacity to live independently;

admitted by agreement with their supervising consultant.

\section{Phase I training}

Training is managed by a military consultant psychiatrist and multi-disciplinary team:

day centre care, with occupational therapy;

individual psychological therapy is continued from the ward;

patients can opt to take part in Phase 2 exercises and can opt to wear uniform;

patients are re-motivated to remain in the army.

The consultant recommends one of the following:

discharge from the army and rehabilitation to civilian life:

return to the ward if the patient has deteriorated graduation to phase 2

\section{Phase 2 training}

Training is managed by military nursing staff with access to medical staff:

5-week course of army exercises and training;

up to $4 \mathrm{~h}$ per week of individual psychological therapy;

uniform and military training are compulsory;

normal military disciplinary rules apply;

patients are trained to army standards in fitness and military skills;

re-familiarisation with the army culture:

nursing staff can observe the soldiers' behaviour in a peer-group situation;

soldiers'ability to fit back into their individual units can be more accurately appraised; safe use of weapons is monitored;

soldiers can return to their unit confident that they are militarily 'up to speed'.

The MTRU staff recommend one of the following:

retention in the army and fully fit for operations;

retention in the army but currently unfit for operations;

discharge from the army

\section{REFERENCES}

Cook, T. D. \& Campbell, D. T. (1979) Quasiexperimentation: Design and Analysis Issues for Field Settings. Boston, MA: Houghton Mifflin.

Defence Analytical Services Agency (200I) UK

Armed Forces Full Time Strengths and Trained

Requirements I Apr OI. London: Ministry of Defence.

Duchess of Kent's Psychiatric Hospital (200I) Annual Statistical Returns. Catterick Garrison: DKPH.

Gilbody, S. \& Whitty, P. (2002) Improving the delivery and organisation of mental health services: beyond the conventional randomised controlled trial. British Journal of Psychiatry, 180, 13-18.

Ministry of Defence (2000) PULHEEMS Administrative Pamphlet. Keynsham: MoD.

Shephard, B. (2000) A War of Nerves: Army Personnel in Psychiatry 1914-1994. London: Jonathan Cape.

World Health Organization (1992) Tenth Revision of the International Classification of Diseases and Related Health Problems (ICD-10). Geneva: WHO. 